\title{
A web survey to assess the perceived mental healthcare among Medical Imaging Professionals during COVID-19 pandemic
}

Dr. Rahul P Kotian ( $\square$ kotian.rahul18@gmail.com )

Srinivas University, Mukka https://orcid.org/0000-0003-2682-158X

Disha Faujdar

Srinivas University, Mukka

Brayal D'souza

Manipal Academy of Higher Education

Dr Sneha P Kotian

MGM Medical College, Navi Mumbai

Dr Sindhura Kunaparaju

DUKE University Hospital, Durham, North Carolina, USA

Leena R David

University of Sharjah, UAE

Keywords: perception, mental health, COVID-19

Posted Date: June 3rd, 2020

DOl: https://doi.org/10.21203/rs.3.rs-32519/v1

License: (1) This work is licensed under a Creative Commons Attribution 4.0 International License.

Read Full License 


\section{Abstract}

Importance: Medical Imaging Professionals (MIP's) providing imaging services exposed to coronavirus disease 2019 (COVID-19) could be psychologically stressed.

Objective: To assess the magnitude of the perceived mental health outcomes among MIP's providing imaging services to patients exposed to COVID-19. We examined the psychological stress, depression and anxiety, experienced by MIP's in the midst of the outbreak.

Background: During the first week of March,2020 the surge of coronavirus disease (COVID-19) cases reached all over the globe with more than 150,000 cases. Healthcare national and international authorities have already initiated awareness and lockdown activities.

Design, Settings, and Participants: This cross-sectional, web survey-based study collected demographic data and mental health measurements from 250 MIP's from April 29, 2020, to May 15, 2020. MIP's working during the pandemic in hospitals for patients with COVID-19 were eligible. An online sample of MIPs was successfully recruited via the authors' networks in India using data collection tool - write google forms. A DASS21 online questionnaire was completed by the participants and then their mental health was assessed.

Results: Of 400 invited MIP's, 314 (78.5\%) participated in the study; and 187 (59.5\%)were included as per inclusion criteria. Hundred and three (55.08\%) participants screened positive for depression, 105 (56.14\%) for anxiety, and 80 (42.78\%) for stress. However, 25 (13.36\%), 18 (9.62\%) and 16 (8.55\%) screened positive for extremely severe for depression, anxiety and stress respectively.

Conclusion and Relevance: In this web survey of MIP's during COVID-19 pandemic, participants reported experiencing high rates of psychological depression, anxiety and stress, especially frontline MIP's directly engaged in the imaging procedures for patients with COVID-19.

\subsection{Background}

Coronavirus disease 2019 (abbreviated "COVID- 19") is a life-threatening respiratory disease caused by a novel coronavirus and was first detected in December 2019 at China. A cluster of about 40 cases of pneumonia of unknown etiology was reported, some of the patients being vendors and dealers in the Huanan Seafood market there. The disease is considered highly infectious, with clinical symptoms of fever, dry cough, fatigue, dyspnea and myalgia $(1,2)$.

The World Health Organization immediately responded to this serious situation and declared it as a public health emergency of international concern on January 30 and requested for collaborative efforts of all countries in the world to prevent the rapid spread of COVID-19 (3). The COVID-19 was declared 
pandemic on March $11^{\text {th }}, 2020$ by WHO and by then had inflicted 100 plus countries with 41 lakh confirmed cases and caused approximately 2,80,000 deaths worldwide.

During a crisis such as the COVID-19 pandemic, it is common for everyone to experience increased levels of distress and anxiety, particularly as a result of social isolation. Physicians and other frontline health care professionals are particularly vulnerable to negative mental health effects as they strive to balance the duty of caring for patients with concerns about their own well-being and that of their family and friends. Not all staff become distressed in the same way or to the same degree. Williams et al. noted the ways in which people responded to emergencies and disasters. He classified them into four main groups as being not upset at all, proportionately distressed, disproportionately distressed andmentally disordered (4).

Insomnia, anxiety, depression, somatization, obsessive-compulsive symptoms are some of the mental health conditions reported by medical healthcare workers during the pandemic (5). The medical healthcare workers who are exposed and in direct contact with the confirmed and suspected coronavirus cases are vulnerable to both high risk infection and mental health problems-worried, scared, experiencing bereavement and trauma. Increase in severity can cause detrimental long-term effect. It can trigger psychological issues of anxiety, fear, panic attacks, posttraumatic stress symptoms, psychological distress, stigma and avoidance of contact, depressive tendencies, sleep disturbances, helplessness, social isolation from family, and fear of contamination of family members (6).

The fear of ostracization can increase anxiety and stress among healthcare workers. The Union Cabinet of India promulgated an ordinance as an amendment in the Epidemic Diseases Act, 1897, that the crime would be incognizable and in case of grievous injuries to health workers, the accused can be sentenced. Damage to clinics of healthcare workers, then a compensation amounting to twice the market value of the damaged property will be taken from the accused. Shortages of PPE, isolation from family, fear of transmitting the virus to the family, rapid expanding workload, incidents of hostility, lack of effective treatment plans are some of the stressors (7). Health care workers can be more worried about their family worrying about them and afraid of taking the virus home and infecting others (8). Psychological assistance services, including telephone, internet, and application based counselling or intervention, have been widely deployed by national and international mental health institutions in response to the COVID19 outbreak. However, evidence based evaluations and mental health interventions targeting front-line Medical Imaging Professionals (MIP's) are relatively scarce. Under- standing the psychological impact of the COVID-19 outbreak among MIP's is crucial in guiding policies and interventions to maintain their psychological well-being.

\subsection{Methods}

\subsection{Ethical considerations}


Confidentiality of the study participants' information was maintained throughout the study by making the participants' information anonymous. An informed consent was obtained from each participant prior to participation. Participants were allowed to terminate the survey at any time they desired. The survey was anonymous, and confidentiality of information was assured.

\subsection{Study Design}

The study is an online cross-sectional, web-based survey conducted during the rapid rise period of the COVID-19 outbreak. An online semi-structured questionnaire was developed by using google forms, with a consent form appended to it.

\subsection{Participants}

MIPs working actively during COVID-19 lockdown were included in the study. This was an online survey as it was not convenient and feasible to do a community-based national sampling survey and snowball sampling due to the global emergency. Purposive sampling technique was used and the questionnaire was sent to 400 participants via Google forms, the identity of the contributors was kept anonymous. Out of which 314 replied and 187 were found eligible as they worked actively during the COVID-19 lockdown. The minimum eligibility to participate in the survey was that the respondents were from the medical imaging fraternity and actively working to provide imaging services during the COVID-19 lockdown period. The link of the questionnaire was sent through e- mails, WhatsApp and other social media to the contacts of the investigators. The participants were encouraged to roll out the survey to as many actively working MIP's as possible. Thus, the link was forwarded to people apart from the first point of contact and so on. On receiving and clicking the link the participants got auto directed to the information about the study and informed consent. After they accepted to take the survey, they filled up the demographic details. Then a set of several questions appeared sequentially, which the participants were to answer.

\subsection{Data collection}

The data collection was done between $29^{\text {th }}$ April to $10^{\text {th }}$ May 2020 . The details of the study were provided to the participants before beginning the survey. The questionnaire was administered in English language.

\subsection{Measures/ Content of the study tool}

The questionnaire included the validated Depression, Anxiety, and Stress Scales (DASS-21) instrument (9). The Depression, Anxiety and Stress Scale - 21 Items (DASS-21) is a set of three self-report scales designed to measure the emotional states of depression, anxiety and stress. Each of the three DASS-21 scales contains 7 items, divided into subscales with similar content as shown in Table 2. Scores for depression, anxiety and stress are calculated by summing the scores for the relevant items. Scores on the DASS -21 were multiplied by 2 to calculate the final score. The questionnaire consisted of two parts namely: demographics and mental health assessment which took approximately 3 minutes to complete. 
Demographic variables included working position, age, gender, education level, marital status, technical title and the type of hospital where the MIP's were working during the pandemic as shown in Table 1.

Table 1. Demographic characteristics of participants

\begin{tabular}{|c|c|c|}
\hline \multicolumn{2}{|l|}{ Characteristics } & Number of participants $N=187$ (\%) \\
\hline \multicolumn{3}{|l|}{ Gender } \\
\hline & Male & $112(59.9)$ \\
\hline & Female & $75(40.1)$ \\
\hline \multicolumn{3}{|l|}{ Age groups } \\
\hline & $18-25$ & $71(38 \%)$ \\
\hline & $26-30$ & $45(24.1 \%)$ \\
\hline & $31-40$ & $44(23.5)$ \\
\hline & $>40$ & $27(14.4 \%)$ \\
\hline \multicolumn{3}{|l|}{ Working position } \\
\hline & Front-line & $130(69.5)$ \\
\hline & Second-line & $57(30.5 \%)$ \\
\hline \multicolumn{3}{|l|}{ Education level } \\
\hline & $<$ or $=$ Postgraduate & $48(25.7)$ \\
\hline & $<$ or $=$ Undergraduate & $68(36.4 \%)$ \\
\hline & Diploma & $71(38 \%)$ \\
\hline \multicolumn{3}{|l|}{ Technical Title } \\
\hline & Intern/trainee & $22(11.8 \%)$ \\
\hline & Technologist & $67(35.8 \%)$ \\
\hline & Radiographer & $86(46 \%)$ \\
\hline & Teaching post & $12(6.4 \%)$ \\
\hline \multicolumn{3}{|l|}{ Marital Status } \\
\hline & Married & $81(43.3 \%)$ \\
\hline & Unmarried & $106(56.7 \%)$ \\
\hline \multicolumn{3}{|l|}{ Type of Hospital } \\
\hline & Diagnostic centre & $45(24.1 \%)$ \\
\hline & Primary hospital & $80(42.8 \%)$ \\
\hline & Secondary hospital & $22(11.8 \%)$ \\
\hline & Tertiary hospital & $40(21.4 \%)$ \\
\hline
\end{tabular}


Table 2. Responses of MIP's to DASS21 questionnaire 


\begin{tabular}{|c|c|c|}
\hline $\begin{array}{l}\text { Question } \\
\text { no }\end{array}$ & Questions (Correct rate, \% of the total sample) & Options (\%) \\
\hline $1(s)$ & I found it hard to relax after stress & $\begin{array}{l}0(15 \%), 1(40.1 \%) \\
2(31.6 \%) \& 3(13.4 \%)\end{array}$ \\
\hline 2 (a) & I was aware of the dryness in my mouth & $\begin{array}{l}0(36.4 \%), 1(24.6 \%) \\
2(25.1 \%) \& 3(13.9 \%)\end{array}$ \\
\hline $3(d)$ & I couldn't seem to experience any positive feeling at all & $\begin{array}{l}0(38 \%), 1(25.1 \%) \\
2(24.1 \%) \& 3(12.8 \%)\end{array}$ \\
\hline $4(\mathrm{a})$ & $\begin{array}{l}\text { I experienced breathing difficulty. (e.g. excessively rapid breathing, } \\
\text { breathlessness in the absence of physical exertion) }\end{array}$ & $\begin{array}{l}0(59.4 \%), 1(15 \%) \\
2(17.6 \%) \& 3(8 \%)\end{array}$ \\
\hline $5(d)$ & I found it difficult to work up the initiative to do things & $\begin{array}{l}0(39 \%), 1(26.7 \%) \\
2(20.3 \%) \& 3(13.9 \%)\end{array}$ \\
\hline $6(s)$ & I tended to over-react to situations & $\begin{array}{l}0(38 \%), 1(34.2 \%) \\
2(19.3 \%) \& 3(8.6 \%)\end{array}$ \\
\hline 7 (a) & I experience trembling (e.g. in the hands) & $\begin{array}{l}0(61 \%), 1(16 \%) \\
2(14.4 \%) \& 3(8.6 \%)\end{array}$ \\
\hline $8(s)$ & $\begin{array}{l}\text { I felt that I was using a lot of nervous energy (excess energy in person } \\
\text { resulting from expectation) }\end{array}$ & $\begin{array}{l}0(39.6 \%), 1(31.6 \%) \\
2(19.3 \%) \& 3(9.6 \%)\end{array}$ \\
\hline 9 (a) & $\begin{array}{l}\text { I was worried about situations in which I might panic and make a fool of } \\
\text { myself }\end{array}$ & $\begin{array}{l}0(42.2 \%), 1(29.4 \%) \\
2(17.6 \%) \& 3(10.7 \%)\end{array}$ \\
\hline $10(d)$ & I felt that I had nothing to look forward to & $\begin{array}{l}0(43.9 \%), 1(22.5 \%) \\
2(19.8 \%) \& 3(13.9 \%)\end{array}$ \\
\hline $11(s)$ & I found myself agitated (feeling or appearing troubled or nervous) & $\begin{array}{l}0(40.6 \%), 1(27.8 \%) \\
2(20.9 \%) \& 3(10.7 \%)\end{array}$ \\
\hline $12(s)$ & I found it difficult to relax & $\begin{array}{l}0(34.8 \%), 1(33.7 \%) \\
2(19.3 \%) \& 3(12.3 \%)\end{array}$ \\
\hline $13(d)$ & I felt down hearted and blue. (feeling discouraged/gloomy) & $\begin{array}{l}0(50.3 \%), 1(24.1 \%) \\
2(16.6 \%) \& 3(9.1 \%)\end{array}$ \\
\hline $14(s)$ & $\begin{array}{l}\text { I was intolerant of anything that kept me from getting on with what I was } \\
\text { doing. }\end{array}$ & $\begin{array}{l}0(48.7 \%), 1(28.9 \%) \\
2(13.4 \%) \& 3(9.1 \%)\end{array}$ \\
\hline 15 (a) & I felt I was close to panic & $\begin{array}{l}0(46.5 \%), 1(27.3 \%) \\
2(19.3 \%) \& 3(7 \%)\end{array}$ \\
\hline $16(d)$ & I was unable to become enthusiastic about anything & $\begin{array}{l}0(43.9 \%), 1(29.4 \%) \\
2(17.1 \%) \& 3(9.6 \%)\end{array}$ \\
\hline $17(d)$ & I felt I wasn't worth much as a person & $\begin{array}{l}0(50.8 \%), 1(24.1 \%) \\
2(17.6 \%) \& 3(7.5 \%)\end{array}$ \\
\hline $18(s)$ & I felt that I was rather touchy (easily upset or offended) & $\begin{array}{l}0(45.5 \%), 1(28.3 \%) \\
2(18.2 \%) \& 3(8 \%)\end{array}$ \\
\hline 19 (a) & $\begin{array}{l}\text { I was aware of the action of my heart in the absence of physical exertion. } \\
\text { (e.g. sense of heart rate increase, heart missing a beat) }\end{array}$ & $\begin{array}{l}0(50.3 \%), 1(25.7 \%) \\
2(14.4 \%) \& 3(9.6 \%)\end{array}$ \\
\hline 20 (a) & I felt scared without any good reason & $\begin{array}{l}0(48.7 \%), 1(24.1 \%) \\
2(18.7 \%) \& 3(8.6 \%)\end{array}$ \\
\hline
\end{tabular}


(d), (a) and (s)- questions on depression, anxiety and stress respectively.

\subsection{Data analysis}

The data analysis was done using descriptive statistics of mean \& SD for continuous variables and for discrete variables frequency and percentage was used. The responses obtained in the study was analysed using SPSS 16.0 .

\subsection{Result}

An online web based survey, related to anxiety experience, stress, depression and perceived mental health care needs in the medical imaging community during the corona pandemic, was conducted. A total of 314 responses were recorded, out of which 187 worked as either front-line or second-line workers during the lockdown pandemic. All the participants were above 18 years of age. The study included only those participants who understood English and had access to the internet. Hence, by default individuals with a higher level of education were included in the study. The lowest educational level in this study was observed to be diploma in medical imaging. The highest qualification of more than $62 \%$ of the population was graduation and above. Among the participants, $40.1 \%$ were females and 59.9 were males. Of 400 invited MIP's, 314 (78.5\%) participated in the study; and 187 (59.5\%)were included as per inclusion criteria.

\subsection{Severity of Measurements for depression, anxiety and stress towards COVID-19 pandemic}

Hundred and three (55.08\%), participants screened positive for depression, 105 (56.14\%), considerate proportion of participants for anxiety, and 140 (74.8\%), participants for stress (Table 3). However, 25 (13.36\%), 18 (9.62\%) and 16 (8.55\%) screened positive for extremely severe for depression, anxiety and stress respectively (Table 4$)$.

Table 3. Prevalence of Depression, Anxiety and Stress, in MIP's ( $N=187)$

\begin{tabular}{|l|l|}
\hline Outcome & Medical Imaging Professionals \\
\hline Prevalence, $\boldsymbol{n}=\%$ \\
\hline Depression & $103(55.08 \%)$ \\
\hline Anxiety & $105(56.14 \%)$ \\
\hline Stress & $80(42.78 \%)$ \\
\hline
\end{tabular}

Table 4. DASS-21 recommended cut-offs for Depression, Anxiety and Stress compared to current study scores $(N=187)$ 


\begin{tabular}{|l|l|l|l|l|l|l|}
\hline & $\begin{array}{l}\text { Depression } \\
\text { DASS-21 }\end{array}$ & $\begin{array}{l}\text { *Depression } \\
\text { N=187(\%) }\end{array}$ & $\begin{array}{l}\text { Anxiety } \\
\text { DASS-21 }\end{array}$ & $\begin{array}{l}\text { *Anxiety } \\
\text { N=187(\%) }\end{array}$ & $\begin{array}{l}\text { Stress } \\
\text { DASS-21 }\end{array}$ & $\begin{array}{l}\text { *Stress } \\
\text { N=187(\%) }\end{array}$ \\
\hline Normal & $0-9$ & $84(44.91 \%)$ & $0-7$ & $82(43.85 \%)$ & $0-14$ & $107(57.21 \%)$ \\
\hline Mild & $10-13$ & $21(11.22 \%)$ & $8-9$ & $8(4.27 \%)$ & $15-18$ & $25(13.36 \%)$ \\
\hline Moderate & $14-20$ & $31(16.57 \%)$ & $10-14$ & $33(17.64 \%)$ & $19-25$ & $26(13.90 \%$ \\
\hline Severe & $21-27$ & $25(13.36 \%)$ & $15-19$ & $18(9.62 \%)$ & $26-33$ & $16(8.55 \%)$ \\
\hline Extremely Severe & $28+$ & $26(13.90 \%)$ & $20+$ & $46(24.59 \%)$ & $34+$ & $13(6.95 \%)$ \\
\hline
\end{tabular}

DASS-21 = Depression, Anxiety, and Stress Scales. * The DASS-21 is a 21-item system that provides independent measures of depression, stress, and anxiety with recommended severity thresholds. Cut-off scores $>9,>7$, and $>14$ indicate a positive screen for depression, anxiety, and stress respectively. Scores on the DASS-21 were multiplied by 2 to calculate the final score. *Depression, *Anxiety \& *Stress- current study score - Current study participants segregated as per the recommended DASS-21 scale.

\subsection{Discussion}

This cross-sectional survey enrolled 187 respondents and revealed a high prevalence of mental health symptoms among MIP's treating patients with COVID-19. Overall, $55.08 \%, 56.14 \%$, and $42.78 \%$ of all participants reported symptoms of depression, anxiety, and stress, respectively. Overall mean DASS-21 scores among MIP's were higher than those in the published literature from previous disease outbreaks, such as the severe acute respiratory syndrome (SARS). As the pandemic continues, important clinical and policy strategies are needed to support health care workers. Our study identified a vulnerable group susceptible to psychological anxiety, depression and stress. Educational interventions should target MIP's to ensure understanding and use of infectious control measures. Psychological support could include counselling services and development of support systems among colleagues.

Most participants were male, were aged 18 to 25 years, were unmarried, and worked in primary care hospitals with a technical title as a radiographer. Our study further indicated that being a healthcare worker and having an intermediate technical title were associated with experiencing severe depression, anxiety, and distress. Working in the front line was an independent risk factor for poor mental health outcomes in all dimensions of interest. Together, our findings present concerns about the psychological well-being of MIP's involved in the acute COVID-19 outbreak. In this study, a significant proportion of participants experienced depression, and stress symptoms, and more than $56.14 \%$ reported psychological anxiety. In a previous study during the acute SARS outbreak, $89 \%$ of health care workers who were in high-risk situations reported psychological symptoms (10). The psychological response of healthcare workers to an epidemic of infectious diseases is complicated. It might be due to stress for feelings of loss or vulnerability about health of self, virus spread and tension about family and others and most importantly being isolated (11). Additionally, acute shortage of necessity supplies and increasing influx of COVID-19 mainly contribute to the pressures and concerns of healthcare providers (12). 
To the best of our knowledge, this is the first study to assess the perceived mental healthcare among MIP's during COVID-19 pandemic. Currently, COVID-19 is a topic of global discussion in the media and among the public, especially among MIPs and patients. With the current case surge of COVID-19 transmission raising tensions for everyone, including health officials and National health systems, an important question arises regarding frontline MIPs in times of mental healthcare and public health crisis. For this reason, we investigated their perceived mental healthcare during this global epidemic.

The strength of this study lies in its large sample of actual working participants recruited during a critical period, the early stage of the COVID-19 outbreak in a given Allied health speciality. The present study was conducted in a standardized manner. Our study has limitations. First, data obtained from selfreported questionnaires were not verified with medical records. Second, the study did not assess socioeconomic status, which may be helpful in evaluating associations of outcomes and tailoring specific interventions. Thirdly, participants who had smartphones, e-mail IDs and the ability to understand English. Lastly, the data presented in this study are self-reported and partly dependent on the participants' honesty and recall ability; thus, they may be subject to recall bias.

Finally, due to the long lockdown closure of higher educational institutions in India during the COVID-19 outbreak, the institutional review board was approached telephonically. Despite these limitations, the present study provides vital information. In conclusion, our study highlights that medical imaging health care personnel are at highest risk for psychological distress during the COVID-19 outbreak. Early psychological interventions targeting this vulnerable group may be beneficial.

\subsection{Conclusion}

In conclusion, our study highlights that MIP's reported high rates of symptoms for anxiety depression, anxiety and stress during the COVID-19 outbreak. Early psychological interventions targeting this vulnerable group may be very beneficial. Protecting allied and health care workers is an important component of public health measures for combating the COVID-19 epidemic. Special interventions to promote mental well-being in MIP's workers exposed to COVID-19 need to be immediately implemented.

\section{Abbreviations}

MIP's-Medical Imaging Professionals

DASS21-Depression, anxiety and stress scales

WHO- World health organization

\section{Declarations}

Ethics approval and consent to participate - The study protocol followed was reviewed and approved by the Research Committee of Srinivas University telephonically and approved online. The consent to 
participate approval was also taken.

Ehical approval reference number- Not applicable

Consent for publication- A detailed explanation about the study was given by the principal investigator after which they provided consent for publication. All the patients included in this research gave written informed consent to publish the data contained within this study.

Availability of data and material- The datasets used and/or analysed during the current study is made available by the corresponding author and attached in the supplementary files.

Competing interests- The authors declare that they have no competing interests in this study.

Funding- Not applicable.

Authors' contributions- RK conceptualized the study. DF, BD, LRD, SK and SPK have given inputs in study design. RK, LRD and DF collected the data. RK analysed the data and wrote the first draft of manuscript and all co- authors contributed in critical review of data analysis and manuscript writing. RK will act as guarantor for this paper.

Acknowledgements - The authors thank all the medical imaging professionals involved in this study for their cooperation and support.

\section{References}

1. Chen N, Zhou M, Dong X, Qu J, Gong F, Han Y, et al. Epidemiological and clinical characteristics of 99 cases of 2019 novel coronavirus pneumonia in Wuhan, China: a descriptive study. Lancet (London, England) [Internet]. 2020 Feb 15 [cited 2020 Apr 6];395(10223):507-13. Available from: https://linkinghub.elsevier.com/retrieve/pii/S0140673620302117

2. Munster VJ, Koopmans M, van Doremalen N, van Riel D, de Wit E. A Novel Coronavirus Emerging in China - Key Questions for Impact Assessment. N Engl J Med [Internet]. 2020 Feb 20 [cited 2020 Apr 6];382(8):692-4. Available from: http://www.nejm.org/doi/10.1056/NEJMp2000929

3. Fahmi I. \#Covid19 Coronavirus Disease 2019. DroneEmprit [Internet]. 2020;2019(April):1-19. Available from: https://pers.droneemprit.id/covid19/

4. Williams R, Bisson J, Kemp V. Principles for responding to people's psychosocial and mental health needs after disasters [Internet]. 2014 [cited 2020 May 13]. Available from:

http://www.rcpsych.ac.uk/publications/

5. Zhang W, Wang K, Yin L, Zhao W, Xue Q, Peng M, et al. Mental Health and Psychosocial Problems of Medical Health Workers during the COVID-19 Epidemic in China. Psychother Psychosom [Internet]. 2020 Apr 9 [cited 2020 May 13];1-9. Available from:

https://www.karger.com/Article/FullText/507639

Page $11 / 12$ 
6. Rana W, Mukhtar S, Mukhtar S. Mental health of medical workers in Pakistan during the pandemic COVID-19 outbreak. Vol. 51, Asian Journal of Psychiatry. Elsevier B. V.; 2020. p. 102080.

7. Mental health challenges for healthcare staff during the COVID-19 pandemic- Management strategies [Internet]. [cited 2020 May 13]. Available from:

https://psychscenehub.com/psychinsights/mental-health-challenges-healthcare-workers-duringcovid-19-pandemic-management-strategies/

8. Chen Q, Liang M, Li Y, Guo J, Fei D, Wang L, et al. Mental health care for medical staff in China during the COVID-19 outbreak. Vol. 7, The Lancet Psychiatry. Elsevier Ltd; 2020. p. e15-6.

9. Lovibond S. Manual for the depression anxiety stress scales. 2nd ed. Sydney N. S. W.: Psychology Foundation of Australia; 1995.

10. Chua SE, Cheung V, Cheung C, McAlonan GM, Wong JWS, Cheung EPT, et al. Psychological effects of the SARS outbreak in Hong Kong on high-risk health care workers. Can J Psychiatry. 2004;49(6):391-3.

11. Wong TW, Yau JKY, Chan CLW, Kwong RSY, Ho SMY, Lau CC, et al. The psychological impact of severe acute respiratory syndrome outbreak on healthcare workers in emergency departments and how they cope. Eur J Emerg Med. 2005;12(1):13-8.

12. Chan-Yeung M. Severe acute respiratory syndrome (SARS) and healthcare workers. Vol. 10, International Journal of Occupational and Environmental Health. Abel Publications Services Inc.; 2004. p. 421-7.

\section{Supplementary Files}

This is a list of supplementary files associated with this preprint. Click to download.

- RESULTS.xIsx

- UntitledformResponses.xlsx 